\title{
Pain management in pediatric day surgery patients at The Maternal and Child Medical Research Center in Mongolia
}

\author{
Jung Un Lee', Sh. Enkhtuvshin², M. Ariuntungalag'2, B. Odgerel'², S. Burmaa², and L. Ganbold ${ }^{3}$ \\ ${ }^{1}$ Department of Anesthesiology and Pain Medicine, School of Medicine, Chungnam National University, Daejeon, Korea, \\ ${ }^{2}$ Department of Pediatric Anesthesiology, Maternal and Child Medical Research Center, ${ }^{3}$ Department of Anesthesia, Health Science \\ University, Ulaanbaatar, Mongolia
}

Background: Pediatric day surgery shortens the hospital stay, reduces the exposure of nosocomial infections and allows for active parental participation. But pain delays the recovery and it increases the morbidity, including nausea and vomiting, and the maladaptive behavioral changes. This study was conducted to compare the effect of rectally administered paracetamol or diclofenac combined with regional nerve block with the traditional pain control method.

Methods: Two hundred forty one randomly selected pediatric patients were allocated into two groups. The empirical pain relief group (the control group, $\mathrm{n}=120$ ) included the patients that received intravenous sulpyrin and/ or meperidine postoperatively. The patients in the multimodal preemptive pain relief group (the study group, $\mathrm{n}=$ 121) received regional nerve blockade with $0.25 \%$ bupivacaine combined with preoperative rectally administered paracetamol $45 \mathrm{mg} / \mathrm{kg}$ or diclofenac $1 \mathrm{mg} / \mathrm{kg} 60 \mathrm{~min}$ before surgery for cases that were to undergo lower abdominal surgery. But only paracetamol or diclofenac was rectally administered preoperatively in the other surgical cases.

Results: The mean time in the recovery room for the study group was shorter than that for the control group. The postoperative pain was hurts even more in $16.7 \%$, worst in $11.8 \%$, a whole lot in $26.5 \%$ and no pain in $27.5 \%$ of the control group patients. But the pain was hurts little more only in $11 \%$, a little bit in $10.0 \%$ and no pain in $88.9 \%$ of the study group patients. The average postoperative VAS score was $0.21 \pm 0.6$ in the study group and $8.36 \pm 1.7$ in the control group, respectively. Vomiting, nausea and fever were more frequently observed in the control group.

Conclusions: The pain intensity of the children who were treated with rectally administered paracetamol or diclofenac combined with regional nerve block before surgery was significantly decreased as compared to that of the children who were treated with the traditional method. (Korean J Anesthesiol 2010; 58: 272-276)

Key Words: Neural blockade, Pediatric postoperative pain, Preemptive analgesia.

Received: January 15, 2010. Revised: January 22, 2010. Accepted: February 1, 2010.

Corresponding author: Sh. Enkhtuvshin, M.D., Department of Pediatric Anesthesiology, Maternal and Child Medical Research Center, Ulaanbaatar, Mongolia. Tel: 976-11-3622, Fax: 976-99198649,E-mail: S_Enkhtuvshin@yahoo.com

(c) This is an open-access article distributed under the terms of the Creative Commons Attribution Non-Commercial License (http:// creativecommons.org/licenses/by-nc/3.0/), which permits unrestricted non-commercial use, distribution, and reproduction in any medium, provided the original work is properly cited. 


\section{Introduction}

The growing popularity of ambulatory surgery has been largely dictated by social and fiscal considerations. Ambulatory surgery is especially suitable for children because many of the surgical procedures they commonly undergo are short and simple, and children are generally in good health [1]. Pediatric surgery in an ambulatory setting shortens the hospital stay, it reduces exposure of nosocomial infections and it allows for active parental participation. The popularity of this subspecialty of surgery has created new challenges and rewarding opportunities for pediatric anesthesiologists. But pain management is one of most important considerations for pediatric ambulatory patients $[2,3]$. The pain following an operation delays recovery, it increases the morbidity, including nausea and vomiting, and it induces behavioral changes in children that are not conducive to recovery [4].

Until the 90, there was a widespread belief that children do not experience pain and so they seldom needed analgesic medications after most surgical procedures. As a result, either no analgesics were used or the recommended dose or route was inadequate to provide effective pain relief [5]. But one of the main goals for current postoperative care is pain free surgery for children.

One of the effective ways for achieving postoperative pain therapy for pediatric surgical outpatients is by combining the use of general anesthesia with the application of a regional block. This would provide for postoperative pain relief and also reduce the requirement for general anesthetics during surgery, and so this results in a more rapid recovery.

Preoperative noxious inputs can contribute to both peripheral and central sensitization that modulates postoperative pain and these can be targets for preemptive analgesia [6]. Various agents, including nonsteroidal antiinflammatory drugs (NSAIDS), have been used in an effort to preempt postoperative pain. It has been shown in animal studies that the noxious stimulus-induced neuroplasticity can be reduced or prevented by preinjury neural block with local anesthesia, or by the administration of i.v. or intrathecal opoids [7-9].

The purpose of this study is set up a program for effective postoperative pain control in pediatric surgical patients for the first time in Mongolia, and the methods of postoperative pain control were a combination of preoperative regional nerve block with preoperative, rectally administered paracetamol or declofenac, and this was compared with the traditional method, which is postoperative IV analgesics.

\section{Materials and Methods}

The study was performed after receiving the approval from our hospital's Ethics Committee. The study included 241 randomly selected, American Society of Anesthesiologists physical status I \& II children (age range: 2-15 yr of age) who had undergone operations on their tonsil, ear, urinary tract, digestive tract etc. during the years 2003 to 2007 . All the children were given atropine i.m. as premedication. The patients were allocated into two groups. The empirical pain relief method group (the control group, $\mathrm{n}=120$ ) included the children who were intravenously administered analgesics like sulpyrin 50$100 \mathrm{mg}$ and/or meperidine $0.5-1 \mathrm{mg} / \mathrm{kg}$ if the patients had pain (equal to hurt little more by Wong-Baker Faces Scale, WBFS) as the traditional approaches to postoperative pain relief. For the multimodal pain relief methods group (the study group, $\mathrm{n}=121$ ), regional nerve blockade with $0.25 \%$ bupivacaine (like caudal epidural block for lower abdominal surgery, and ilioinguinal, iliohypogastric and genitofemoral nerve block for groin and pelvic area surgery and penile block for circumcision) was performed as a supplement to general anesthesia. This was combined with preoperative, rectally administered paracetamol $45 \mathrm{mg} / \mathrm{kg}$ or diclofenac $1 \mathrm{mg} / \mathrm{kg} 60 \mathrm{~min}$ before surgery for the lower abdominal surgical cases. But only paracetamol or diclofenac was administered rectally for the other surgical cases. Oral paracetamol tablets were given for postoperative pain control if it was necessary.

Thiopental sodium was used for induction of anesthesia and succinylcholine was used for tracheal intubation in all the patients. Halothane with $100 \%$ oxygen was administrated using the intermittent positive pressure ventilation technique for maintenance of anesthesia. Pancuronium was used for muscle relaxation.

The postoperative pain was determined after recovery from anesthesia, by same anesthesiologist who was not involved in this study, by using a questionnaire (Visual Analogue ScaleVAS, Numeric Rating Scale-NRS) or measurement (WBFS) of the pain intensity as objective indicators. The pain intensity according to a VAS score of $0-1$ was evaluated as no pain, $1-3$ was hurts a little bit, $3-5$ was hurts a little more, $5-7$ was hurts even more, 7-9 was hurts a whole lot and above 9 was hurts the worst. In case of VAS > 6.0, we gave paracetamol or diclofenac, or a local block to decrease the pain intensity. The patients were discharged from the recovery room after the pain had decreased to hurts a little bit according to the WBFS.

Statistical analysis was performed using SPSS 15.0 for Windows (SPSS Inc., Chicago, IL). The data is expressed as means \pm SDs. Age and weight were compared using the independent $t$ test. Gender and the type of surgery were compared using Fisher's exact test. The operation time and time in the recovery room were compared using the Mann-Whitney test. The postoperative pain intensity was compared with the Chi-square test. $\mathrm{P}$ values $<0.05$ were considered statistically significant. 


\section{Results}

The majority of procedures in both groups were tonsillectomies, hernia repairs and circumcisions. The additional procedures included tympanoplasties, myringotomies, orchiopexies and umbilical hernia repairs. In both groups, the males made up the majority of the myringotomy, orchidophexy and umbilical hernia surgical cases, but the females made up the majority of the tonsillectomy cases. The males made up $70.1 \%$ of all the cases. The children aged between 2 and 4 made up $17.1 \%$ of the cases. The mean operation time was $52.7 \pm 3.4 \mathrm{~min}$ in the control group and $49.9 \pm 3.7 \mathrm{~min}$ in the study group, respectively. The mean time in the recovery room was $30.1 \pm$ 18.1 min in the study group, which was significantly shorter than the mean time in the recovery room $(59.5 \pm 37.2 \mathrm{~min})$ in the control group (Table. 1).

The postoperative pain was hurts even more for $16.7 \%$, hurts

Table 1. The Patients' Characteristics and Surgical Procedures, by the International Classification of Diseases

\begin{tabular}{lccc}
\hline $\begin{array}{l}\text { Demographic characteristics } \\
\text { of the patients }\end{array}$ & $\begin{array}{c}\text { Control G } \\
\mathrm{N}=120 \\
\mathrm{~N}(\%)\end{array}$ & $\begin{array}{c}\text { Study G } \\
\mathrm{N}=121 \\
\mathrm{~N}(\%)\end{array}$ & P value \\
\hline $\begin{array}{l}\text { Mean age } \\
\text { Gender }\end{array}$ & $8.3 \pm 5.3$ & $8.5 \pm 4.3$ & 0.658 \\
$\quad$ Male & $82(68.4)$ & $87(71.9)$ & 0.451 \\
Female & $38(31.6)$ & $34(28.1)$ & \\
Weight (kg) & & & \\
$0-10$ & $8(6.6)$ & $7(5.7)$ & 0.413 \\
$\quad 11-70$ & $112(93.4)$ & $114(94.3)$ & 0.397 \\
Surgery & $50(41.7)$ & $58(47.9)$ & \\
$\quad$ Tonsil, the ear, mastoid & $22(18.3)$ & $13(10.7)$ & \\
$\quad$ Urine tract system disease & $10(8.3)$ & $11(9.1)$ & \\
Digestive system disease & $38(31.7)$ & $39(32.3)$ & \\
$\quad$ Congenital anomaly & $52.7 \pm 3.4$ & $49.9 \pm 3.7$ & 0.571 \\
Mean operation time & $59.5 \pm 37.2$ & $30.1 \pm 18.1$ & $0.001^{*}$ \\
Mean time in the recovery room & 5 &
\end{tabular}

Control G: the empirical pain relief method group sulpyrin, meperidine postoperatively, Study G: the multimodality pain relief method group (preemptive analgesia, nerve block + rectal paracetamol or diclofenac). ${ }^{*} \mathrm{P}<0.01$ compared with the control group.

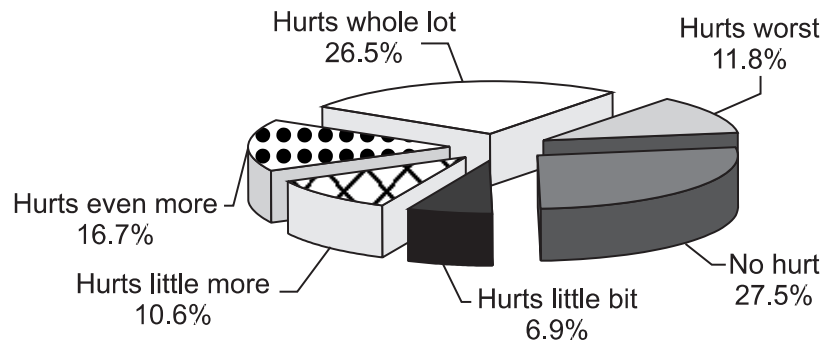

Fig. 1. Postoperative pain intensity in the control group. Control G: the empirical pain relief method group (sulpyrin, meperidine postoperatively). worst for $11.8 \%$, hurts a whole lot for $26.5 \%$, hurts a little more for $10.6 \%$ and hurts a little bit for $6.9 \%$ of the control group patients, respectively. Twenty seven point five percent of the patients had no pain in the control group (Fig. 1). On the other hand, $11 \%$ and $10.0 \%$ of the patients had pain that was hurts a little more and hurts a little bit, respectively, in the study group. There was no pain in $88.9 \%$ of the patients in the study group (Fig. 2). The average VAS score was $0.21 \pm 0.6$ in the preemptive analgesia group. However, the average VAS score was $8.36 \pm 1.7$ in the control group. Vomiting, nausea and fever were observed more frequently in the control group (Table. 2).

\section{Discussion}

Regional block techniques should be used in the outpatient setting. Bupivacaine $0.25 \%$ with or without epinephrine is commonly used for pediatric ambulatory patients. For cooperative adolescents, spinal or epidural anesthesia alone may be used for an operation in the outpatient setting [10]. Peripheral nerve block for pain management has received recognition because of its ability to provide superior analgesia with fewer side effects, when compared with traditional intravenous opioids for pain management [11].

The concept of preemptive analgesia is an attractive one

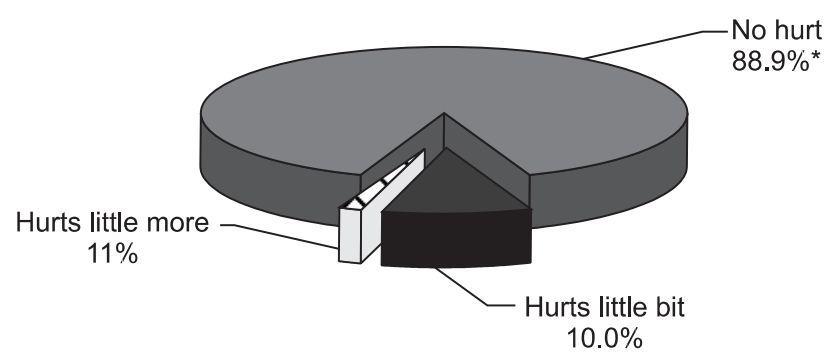

Fig. 2. Postoperative pain intensity in the study group. There was significantly decreased pain intensity in the study group. Study G: the multimodality pain relief (preemptive analgesia, nerve block + rectal paracetamol or diclofenac) group. ${ }^{*} \mathrm{P}<0.01$ compared with the control group.

Table 2. Nausea, Vomiting (N/V) and Fever that Occurred after Surgery

\begin{tabular}{lccc}
\hline & $\begin{array}{c}\text { Control G } \\
\mathrm{N}=120 \\
\mathrm{~N}(\%)\end{array}$ & $\begin{array}{c}\text { Study } \mathrm{N}=121 \\
\mathrm{~N}(\%)\end{array}$ & P value \\
\hline $\mathrm{N} / \mathrm{V}$ & $82(68.3)$ & $4(3.3)$ & 0.00 \\
Fever & $26(21.4)$ & $1(0.8)$ & 0.00
\end{tabular}

Control G: the empirical pain relief method group sulpyrin, meperidine postoperatively, Study G: the multimodal pain relief method group (preemptive analgesia, nerve block + rectal paracetamol or diclofenac). $* \mathrm{P}<0.01$ compared with the control group. 
because if it is proved to be effective in the clinical setting, it may protect patients from the deleterious effects of a surgical incision and other noxious perioperative events long after the operation has been performed. Taken further, the notion of painless surgery is a distinct possibility. Yet clear clinical evidence for preemptive analgesia has not yet been established, despite what appears to be convincing experimental evidence $[7,8,12]$. Much of the initial work supporting this concept of "pain prevention" originates from animal studies [13], which have demonstrated this concept under specific conditions in experimental models. Surgical trauma differs from the stimuli used in experimental models, in that the afferent input to the CNS during surgery may be extensive, and this involves mixed cutaneous, muscular and visceral components. The degree of surgical trauma and the site of operation are also important in influencing the amount of nociceptive input [14]. A few studies have evaluated the use of regional anesthesia in pediatric ophthalmic surgery. Preemptive peribulbar block was evaluated as an adjunct to general anesthesia in children who were undergoing brief ophthalmic procedures and this technique showed a significant reduction of the postoperative pain scores [15]. However, there was no difference in the postoperative pain or analgesic requirement when using or not using retrobulbar block in children ( $5 \pm 3$ years) who were undergoing strabismus surgery [16].

Acetaminophen is frequently used as an adjuvant for postoperative analgesia in pediatric patients. It is thought to act through the inhibition of cyclooxygenase in the central nervous system and this produces analgesia that is comparable with that of nonsteroidal antiinflammatory drugs. Inhibition of prostaglandin synthesis in other tissues does not occur, and so acetaminophen produces no antiinflammatory effects or effects on platelet function that may be associated with the use of nonsteroidal antiinflammatory drugs [17].

Rectal administration of acetaminophen leads to slow absorption and erratic blood levels, and it takes a long time to achieve effective therapeutic levels. The rectal route of acetaminophen administration cannot be recommended when a rapid onset of analgesia is desired [18]. A single rectal dose of acetaminophen $45 \mathrm{mg} / \mathrm{kg}$ may be appropriate if a delayed and sustained effect is required [19]. But recent evidence indicates that a larger dose than what is commonly administered is required: up to $60 \mathrm{mg} /$ kg rectally [20] with an onset time of 60-90 minutes, and the peak effect is not reached early after rectal administration [19]. In our study, paracetamol $45 \mathrm{mg} / \mathrm{kg}$ or diclofenac $1 \mathrm{mg} / \mathrm{kg}$ was given rectally $60 \mathrm{~min}$ before surgery, and the analgesic effect was good. Rectal administration is most suitable for children $1-3$ yr of age. Many older children may be more upset by introducing the drug into their rectums than by receiving an injection [21]. Chloral hydrate has a disagreeable taste and it is often unsatisfactory if given less than sixty minutes prior to surgery [22].

Transmucosal administration of short acting narcotics is also an effective way of producing preoperative sedation in pediatric patients, and only a few analgesics have currently been evaluated. Although the successful use of oral transmucosal fentanyl $(15-20 \mu \mathrm{g} / \mathrm{kg})$ as well as nasal sufentanil $(1.5-3 \mu \mathrm{g} /$ $\mathrm{kg}$ ) has been reported, much additional experience is still needed before the use of these techniques is firmly established [23]. IV ketorolac with midazolam premedication was found to be effective, but it requires IV access, which is not otherwise indicated for children in this setting [24].

The traditional method of postoperative pain relief using sulpyrin injection was used for most operations until 2000. According to the first study by L. Ganbold in 1997, 94.5\% of patients have moderate pain postoperatively after preoperative sulpyrin injection. The intensity of pain was high after the common pediatric ambulatory surgeries such as hernia repair, orchiopexy and phimosis [25]. We were able to reduce the pain intensity with rectal administration of paracetamol or diclofenac combined with regional nerve block.

Recording our study, there were some reported incidences of feeling pain after the first $6-8$ hours of postoperative pain relief. The pain had increased on the VAS by $1-3$ points, which is not very high. We think the following factors influenced this incidence: a lack of knowledge and awareness of the parents and the lack of well trained staff in the wards. Most of the patients who were undergoing pediatric ambulatory surgery were male except for the tonsillectomy cases. So the incidence of post-surgical pain was higher among the male children than that among the females.

Nausea, vomiting and fever occurred quite often in the control group. Active movements and crying because of ineffectively controlled postoperative pain seemed to easily cause these problems.

The postoperative pain of children who undergo pediatric day surgeries in the Maternal and Child Medical Research Center in Mongolia could be evaluated and measured by the WBFS, VAS and NRS when they feel pain and this is a clinical indication of pain management. It is imperative to choose the appropriate measurement methodology according to the age of the child, and the postoperative pain intensity in children needs to surveyed and registered in every case.

In conclusion, the post surgical pain intensity of the children who were treated with traditional methods, like weak analgesics, after surgeries was very high. But this pain was effectively treated in the children who received rectally administered paracetamol or diclofenac combined with regional nerve block before surgery. 


\section{References}

1. Hannallah RS, Epstein BS. The pediatric patient. In: Anesthesia for ambulatory surgery. 2nd ed. Edited by Wetchler BW: Philadelphia, JB Lipincott. 1991, pp 131-95.

2. Anand KJ, Hickey PR. Pain and its effects in the human neonate and fetus. N Engl J Med 1987; 317: 1321-9.

3. Schechter NL. The undertreatment of pain in children: an overview. Pediatr Clin North Am 1989; 36: 781-94.

4. Kotiniemi LH, Ryhanen PT, Moilanen IK. Behavioural changes in children following day case surgery: a 4 week follow up of 551 children. Anaesthesia 1997; 52: 970-6.

5. Raafat SH. Postoperative analgesia in the paediatric patient. Can J Anaesth 1992; 39: 641-2.

6. Woolf CJ. Recent advances in patho physiology of acute pain. Br J Anaesth 1989; 63: 139-46.

7. Coderre TJ, Melzack R. Cutaneous hyperanalgesia: contributions of the peripheral and central nervous systems to the increase in pain sensitivity after injury. Brain Res 1987; 404: 95-106.

8. Coderre TJ, Vaccarino AL, Melzak R. Central nervous system plasticity in the tonic pain response to subcutaneous formalin injection. Brain Res 1990; 535: 155-8.

9. Dickenson AH, Sullivan AF. Subcutaneous formalin induced activity of dorsal horn neurones in the rat: differential response to an intrathecal opiate administered pre or post formalin. Pain 1987; 30: 349-60.

10. Semyon F, Ronald S, Litman DO. Current issues in pediatric ambulatory anesthesia. Anesthesiol Clin North America 2003; 21: 305-10.

11. Richman JM, Liu SS, Courpas G, Wong R, Rowlingson AJ, McGready J, et al. Does continuous peripheral nerve block provide superior pain control to opioids? A meta analysis. Anesth Analg 2006; 102: 248-57.

12. Woolf CJ, Chong MS. Preemptive analgesia treating postoperative pain by preventing the establishment of central sensitization. Anesth Analg 1993; 77: 362-79.

13. Cook AJ, Woolf CJ, Wall PD. Prolonged C fibre mediated facilitation of the flexion reflex is not due to changes in afferent terminal or motor neuron excitability. Neurosci Lett 1986; 70: 91-6.

14. Espinet A, Henderson DJ, Faccenda KA, Morrison MM. Does pre- incisional thoracic extradural block combined with diclofenac reduce postoperative pain after abdominal hystrectomy? Br J Anaesth 1996; 76: 209-13.

15. Deb K, Subramaniam R, Dehran M, Tandon R, Shende D. Safety and efficacy of peribulbar block as adjunct to general anaesthesia for paediatric ophthalmic surgery. Paediatr Anaesth 2001; 11: 1617.

16. Ates T, Unal N, Cuhruk H, Erkan N. Postoperative analgesia in children using preemptive retrobulbar block and local anesthetic infiltration in strabismus surgery. Reg Anesth Pain Med 1998; 23: 569-74.

17. Clissold SP. Paracetamol and phenacetin. Drugs 1986; 32(Suppl 4): 46-59.

18. Prins SA, Van Dijk M, Van Leeuwen P, Searle S, Anderson BJ, Tibboel D, et al. Pharmacokinetics and analgesic effects of intravenous propacetamol vs rectal paracetamol in children after major craniofacial surgery. Paediatr Anaesth 2008;18: 582-92.

19. Korpela R, Korvenoja P, Meretoja OA. Morphine-sparing effect of acetaminophen in pediatric day case surgery. Anesthesiology 1999; 91: 442-7.

20. Montgomery CJ, McCormack JP, Reichert CC, Marsland CP. Plasma concentrations after high dose (45 mg.kg-1) rectal acetaminophen in children. Can J Anaesth 1995; 42: 982-6.

21. Raafat SH, Ramesh IP. Low dose intramuscular ketamine for anesthesia preinduction in young children undergoing brif outpatient procedures. Anesthesiology 1989; 70: 598-600.

22. Anderson BJ, Exarchos H, Lee K, Brown CK. Oral premedication in children: a comparison of chloral hydrate, diazepam, alprazolam, midazolam and placebo for day surgery. Anaesth Intensive Care 1990; 18: 185-93.

23. Henderson JM, Brodsky DA, Fisher DM, Berett CM, Hertzka RE. Preinduction of anaesthesia in pediatric patients with nasally administered sufentanil. Anesthesiology 1988; 68: 671-5.

24. Davis PJ, Greenberg JA, Gendelman M, Fertal K. Recovery characteristics of sevoflurane and halothane in preschoolaged children undergoing bilateral myringotomy and pressure equalization tube insertion. Anesth Analg 1999; 88: 34-8.

25. Ganbold L. Dissertation on postoperative pain management in adults. J Mong Anaesth 2002; 1: 25-34. 